\title{
CHROMOSOME WEIGHTS AND MEASURES IN THE TRITICINAE
}

\author{
C. PEGINGTON and H. REES \\ Department of Agricultural Botany, University College of Wales, Aberystwyth
}

Received 7.v.69

\section{INTRODUGTION}

IT is widely accepted that the modern cultivated wheats such as Triticum aestivum $(A A B B D D)$ and Triticum durum $(A A B B)$ are, respectively, allohexaploids and allo-tetraploids derived from hybrids between diploid species of the Triticinae viz. T. monococcum $(A A)$, Aegilops squarrosa $(D D)$ and Aegilops speltoides (BB) (Riley, Unrau and Chapman, 1958; Jenkins, 1966). A question which arises is to what extent, if any, the chromosomes of the ancestral diploid species have changed subsequent to the hybridisation and polyploidy which gave rise to these modern allopolyploids. To answer this question three types of comparisons between the chromosomes of the diploids and polyploids can usefully be made. They are comparisons with respect to the size of chromosomes, their total dry mass and the DNA component of their mass.

Using chromosome length as a measure of chromosome size, Bhaskaran and Swaminathan (1960) show significant variation between the chromosomes of the diploids, the tetraploids and the hexaploids. Pai and Swaminathan (1960) use this evidence together with information on DNA content obtained by Bhaskaran and Swaminathan (loc. cit.) to support an hypothesis which claims that a diminution in chromosome size and DNA content has occurred during the evolution of the wheats. The DNA results obtained by Bhaskaran and Swaminathan are, however, questionable (Rees and Walters, 1965; see also Upadya and Swaminathan, 1963) so that the main evidence for a chromosome diminution in the allopolyploids rests on comparisons between chromosome size based on measurements of length. The validity of length alone as a measure of chromosome size is also questionable. It does not take into account variation attributable to differences in chromosome coiling. Estimates of size based on chromosome volume are, in this respect, preferable and have been used in this present work.

Measurements of the dry mass of chromosomes provide further and more precise information about structural changes, such as large scale diminution or, for that matter, accretion of chromosome material that may have taken place during this evolutionary process. In conjunction with DNA measurements the estimates of dry mass of the chromosomes also make it possible to ascertain whether the components of the chromosome mass, the DNA and non-DNA material, vary independently of one another between the diploids and their polyploid descendants. In other words, they permit comparison of a qualitative as well as a quantitative kind between the modern and ancestral forms. Chromosome measurements were made in several species of the Triticinae other than those already mentioned. Together they provide useful information upon the relations and interrelations between various aspects of chromosome organisation within the family. 


\section{Materials AND methods}

\section{(a) Materials}

The species used in this investigation are shown in table 1. The seeds were all obtained from Dr R. Riley of the Plant Breeding Institute, Cambridge, to whom we are grateful.

TABLE 1

\section{The species}

Triticum aestivum
T. durum
T. dicoccoides
T. timopheevi
T. monococcum
T. aegilipoides
Aegilops speltoides
Ae. squarrosa
Ae. bicornis
Agropyron triticeum

$\begin{array}{ll}6 X=42 & A A B B D D \\ 4 X=28 & A A B B \\ 4 X=28 & A A B B \\ 4 X=28 & A A G G(?) \\ 2 X=14 & A A \\ 2 X=14 & A A \\ 2 X=14 & B B \\ 2 X=14 & D D \\ 2 X=14 & ? \\ 2 X=14 & ?\end{array}$

(b) Methods

\section{(i) Estimation of chromosome volumes}

The total chromosome volume was estimated from the total chromatid length, measured at metaphase by means of a micrometer eyepiece, and from the mean chromatid width obtained from a random sample of ten chromatids per cell. Calculation of the volumes in each metaphase was made on the assumption that the chromatids are cylindrical in form. Metaphases were scored in three root-tips in at least three seedlings in each species (see Plate I).

Slides were prepared by the Feulgen method after immersion of the root tips in water at $4^{\circ} \mathrm{C}$. for 24 hours and fixation in acetic alcohol. Preparations were made permanent by mounting in Euparal. All the chromosomes measurements were made from these permanent preparations. It is important, in this context, to note that these measurements are not necessarily directly comparable to others made on temporary slides or from slides prepared by other staining methods.

\section{(ii) Estimation of nuclear dry mass}

Estimates of total nuclear dry mass were made by interference microscopy (see Barer, 1956; Davies; 1958) in nuclei isolated from root tips by a technique devised by McLeish (1963). All estimates of volume and of dry mass were made in seedlings aged 5-7 days. This minimises any variation in chromosome size or mass due to "age" (Bennett and Rees, 1967).

\section{Results}

(a) Observations

(1) Chromosome volume

The chromosome volumes of nine species investigated are presented in table 2. An analysis of variance of the data showed that $(a)$ there is no 


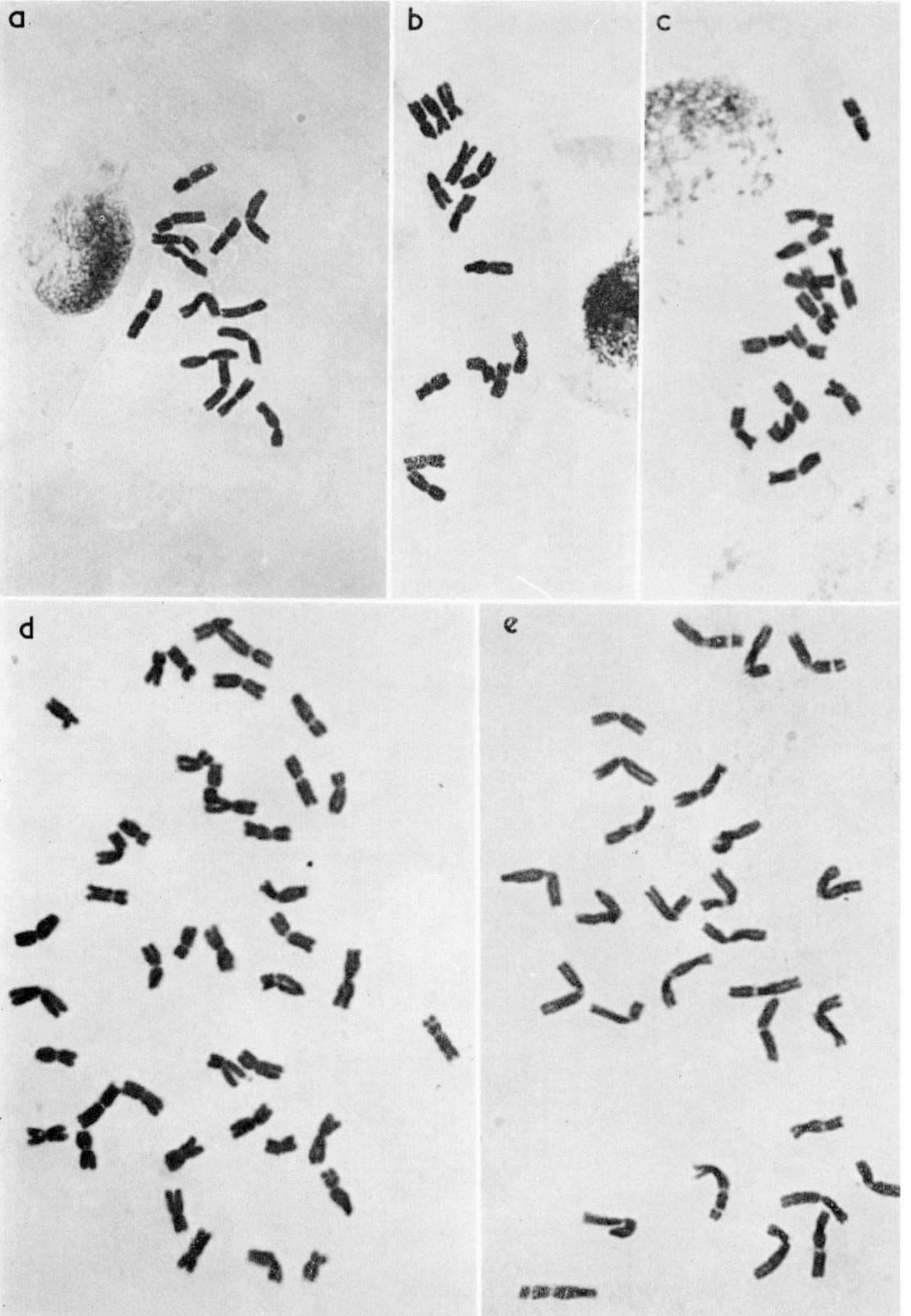

Root tip metaphases in (a) Triticum monococcum, (b) Aegilops speltoides, (c) Aegilops squarrosa, (d) Triticum aestivum, (e) Triticum durum $(\times c a .3000)$. 
significant variation between the two $A A B B$ tetraploids $T$. durum and $T$. dicoccoides $(\mathrm{P}<0 \cdot 2)$. There is, however, a significant difference between the chromosome volume of $T$. timopheevi and those of the $A A B B$ tetraploids $(\mathrm{P}<0.01)$. This would tend to support the view that $T$. timopheevi has a different ancestry from the other tetraploids (Lilienfield and Kihara, 1934).

TABLE 2

Volume and total length of chromosomes at metaphase

\begin{tabular}{|c|c|c|}
\hline & $\begin{array}{c}\text { Total } \\
\text { chromosome } \\
\text { volume } \\
\text { (cubic microns) }\end{array}$ & $\begin{array}{c}\text { Total } \\
\text { chromosome } \\
\text { length } \\
(\mu)\end{array}$ \\
\hline T. aestivum & $52.553 \pm 0.58$ & $201 \cdot 1 \pm 4 \cdot 51$ \\
\hline T. durum & $36 \cdot 370 \pm 1.52$ & $158.9 \pm 5.45$ \\
\hline$T$. dicoccoides & $38.708 \pm 0.79$ & $159.1 \pm 6.79$ \\
\hline T. timopheevi & $30.411 \pm 0.60$ & $183.9 \pm 15.25$ \\
\hline T. monococcum & $19 \cdot 727 \pm 0.40$ & $81.4 \pm 1.91$ \\
\hline T. aegilipoides & $19.029 \pm 0.42$ & $86.4 \pm 2.44$ \\
\hline Ae. speltoides & $16.070 \pm 0.30$ & $73.1 \pm 0.93$ \\
\hline Ae. squarrosa & $16 \cdot 135 \pm 0.53$ & $68.8 \pm 2.72$ \\
\hline Ae. bicornis & $16.741 \pm 0.44$ & $96.2 \pm 3.61$ \\
\hline
\end{tabular}

(b) There is no significant variation between the $A A$ diploids $T$. monococcum and $T$. aegilipoides $(\mathrm{P}>0 \cdot 20)$. Nether is there a significant variation in chromosome volume between $A e$. speltoides $(B B), A e$ bicornis ( $B B$ ?') and Ae. squarrosa $(D D) \cdot(\mathrm{P}=>0.40)$, although the average chromosome volume of these three species is significantly lower than that of the $A A$ diploids.

\section{(b) Expectations}

Assuming no chromosome changes affecting their volume have taken place subsequent to the initial hybridisation, we should expect the sum of chromosome volumes in $A A$ and $B B$ to equal that found in $A A B B$ tetraploids and that the chromosome volumes of $A A B B$ plus that of $D D$ should equal the volume in the present $A A B B D D$ hexaploid. The expected values along with those observed appear in table 3 .

TABLE 3

Observed and expected chromosome volumes in the polyploids

$\begin{array}{lcc} & \text { Expected } & \text { Observed } \\ \text { (a) } A A(T . \text { monococcum })+B B(\text { Ae. speltoides }) & 35.80 & 36.37 \\ \text { (b) } A A B B^{*}+D D \text { (Ae. squarrosa) } & 53.67 & 52.55\end{array}$

* Mean volume of $T$. durum and $T$. dicoccoides.

The observed values do not differ significantly from those expected. For $a, \mathrm{P}=>0.9$; for $b, \mathrm{P}=>0.30$. There is no indication of a reduction or indeed of any change in chromosome size as a consequence of polyploidy. 


\section{(2) Chromosome length}

Measurements of chromosome length made during the present work (see tables 2 and 4) agree with those of Bhaskaran and Swaminathan (1960) in so far as the observed values in the hexaploid are significantly lower than the lengths of $A A B B+D D(\mathbf{P}=<0.001)$. The shorter chromosome lengths observed in the hexaploid cannot, in the light of the results on chromosome volumes, be interpreted as reflecting a diminution of chromosome material. Rather do they indicate a difference in organisation, presumably in coiling.

TABLE 4

Observed and expected chromosome lengths in the polyploids

$\begin{array}{lcc} & \text { Expected } & \text { Observed } \\ A A(T . \text { monococcum })+B B \text { (Ae. speltoides) } & 154.5 & 158.9 \\ A A B B^{*}+D D(\text { Ae. squarrosa }) & 227.8 & 201.1\end{array}$

* Mean of $T$. durum and $T$. dicoccoides.

They are of interest in so far as they may well reflect a greater compaction of chromosomes conferring mechanical advantages with increasing chromosome number (Darlington, 1937).

There is no significant difference between the observed and expected values in the tetraploids $(P=>0.30)$.

\section{(3) Dry mass of nuclei}

Estimates of the nuclear dry mass in root tip meristems of seven species of the Triticinae are given in table 5. In table 6 are the expected and observed values for the nuclear dry mass in tetraploid and hexaploid cultivated wheats.

TABle 5

Nuclear dry mass and the nucleolar dry mass of isolated 4C nuclei. Data from 5 nuclei in each of 5 seedlings in each species

$\begin{array}{lccc}\begin{array}{c}\text { Nuclear mass } \\ \times 10^{-11} \mathrm{gm} .\end{array} & \begin{array}{c}\text { Nucleolar mass } \\ \times 10^{-11} \mathrm{gm} .\end{array} & \begin{array}{c}\text { Total mass } \\ \times 10^{-11} \mathrm{gm} .\end{array} \\ \text { T. aestivum } & 18.48 \pm 0.30 & 7.91 \pm 0.30 & 26.39 \\ \text { T. durum } & 12.47 \pm 0.41 & 4.96 \pm 0.91 & 17.43 \\ \text { T. timopheevi } & 12 \cdot 06 \pm 0.62 & 5 \cdot 11 \pm 0.48 & 17 \cdot 17 \\ \text { T. monococcum } & 7.25 \pm 0.17 & 4.05 \pm 0.25 & 11.30 \\ \text { Ae. speltoides } & 5.96 \pm 0.14 & 3.05 \pm 0.17 & 9 \cdot 01 \\ \text { Ae. squarrosa } & 5 \cdot 29 \pm 0.19 & 3.28 \pm 0.22 & 8.57 \\ \text { Ag. triticeum } & 5.31 \pm 0.19 & 2.92 \pm 0.21 & 8.23\end{array}$

From table 6 it will be seen that the observed values, in each case, are somewhat lower than expected. Analyses of variance, however, show that there is no significant difference between observation and expectation $(a, \mathrm{P}>0.05 ; b, \mathrm{P}>0.05)$. Comparisons of nuclear mass, like those of chromosome volume, show no detectable change in the material content of ancestral genomes subsequent to hybridisation and polyploidy. 
TABLE 6

The observed and expected nuclear dry mass in the polyploids

(a) $A A$ (T. monococcum $)+B B$ (Ae. spelioides)

Expected Observed

(b) $A A B B(T$. durum) $+D D$ (Ae. squarrosa)

$13 \cdot 21$

$12 \cdot 47$

$17 \cdot 76 \quad 15 \cdot 48$

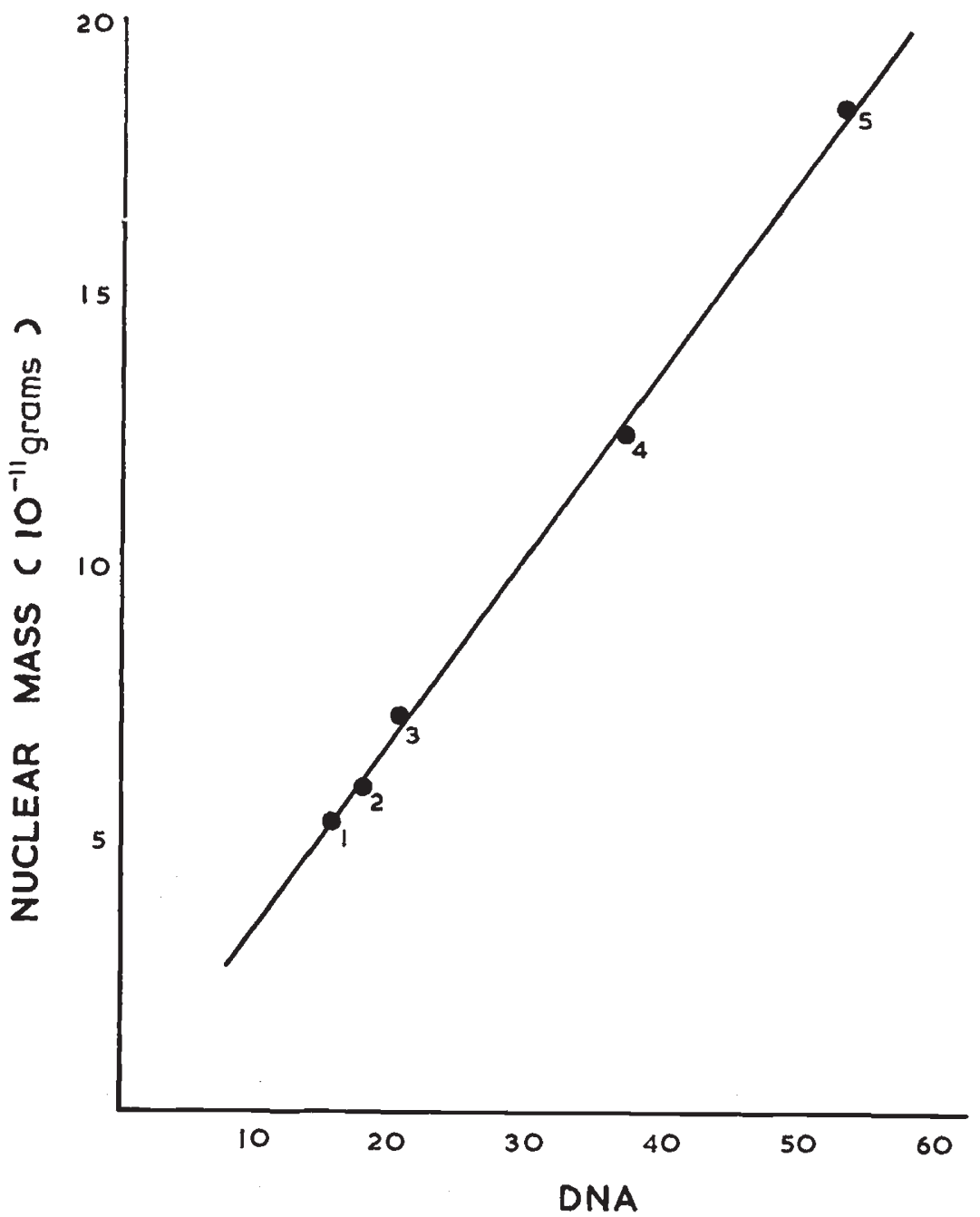

Fig. 1.-The nuclear dry mass of $4 C$ interphases in root tips plotted against DNA amounts (arbitrary units). $1=$ Aegilops squarrosa, $2=$ Aegilops speltoides, $3=$ Triticum monococcum, $4=$ Triticum durum, $5=$ Triticum aestivum. 


\section{(4) Correlations}

(a) Volume, mass and DNA

Investigations over a wide range of species show, in general, a close correlation between chromosome volume, nuclear DNA content and the nuclear dry mass (McLeish, 1963; Rees et al., 1966; Rothfels et al., 1966). Using the DNA estimates of Rees and Walters (1965), comparisons have been made between these three characters in five of the Triticinae species. From the graphs in figs. 1, 2 and 3 it is clear that all three characters are very closely related in a simple linear fashion.

The earlier results, dealing with each of the three characters separately, indicated that the chromosomes have remained constant in volume, total mass and DNA content, throughout the evolution of the cultivated wheats.

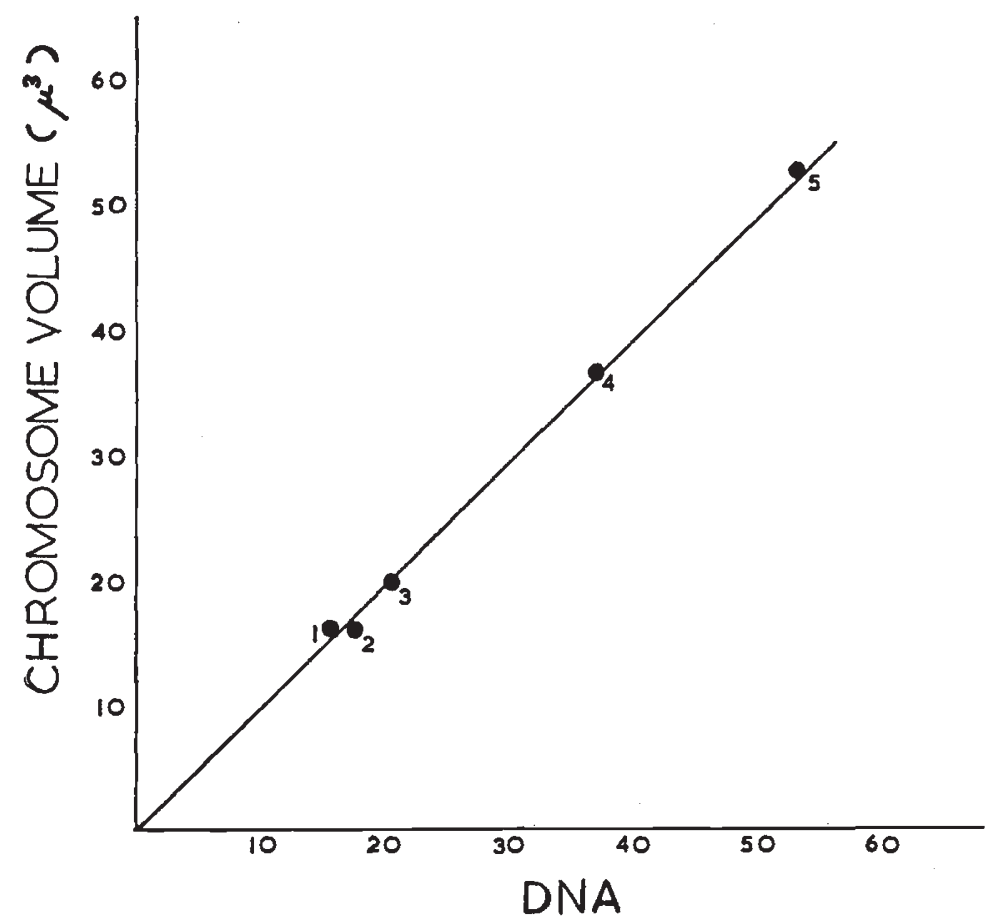

Fro. 2.-Metaphase chromosome volume plotted against nuclear DNA content. Code as in Fig. 1.

It follows from the comparisons represented in figs. 1, 2 and 3 that there is also a strict parallel in the variation of the characters relative to one another, a constancy with respect to the ratios, nuclear mass/chromosome volume, DNA/ chromosome volume and DNA/nuclear mass; a constancy pertaining both to diploids and polyploids, to the cultivated and to the ancestral forms.

\section{(b) Chromosome length and DNA}

When chromosome length is plotted against nuclear DNA (fig. 4) the relationship is not of a simple linear kind as was the case with chromosome volume. Fig. 4 shows a distinct and significant curvilinearity $(P=<0.05)$. 
The same is true of length and nuclear dry mass (fig. 5). Per unit length the mass, including DNA, is significantly greater in the hexaploid than in the diploid and tetraploid species. This information serves in effect to confirm the earlier conclusion that the chromosome organisation changes, becoming

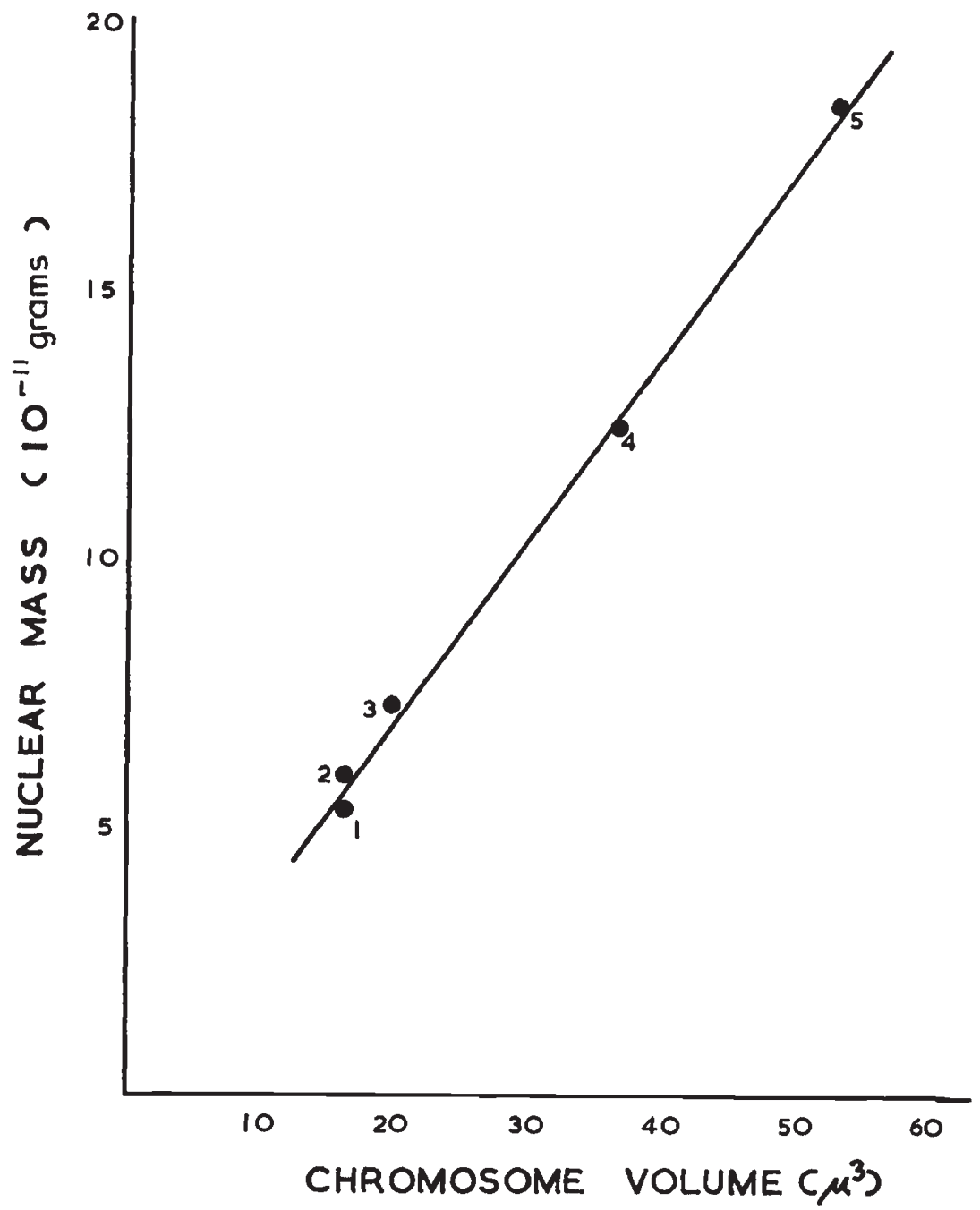

Fig. 3. - The nuclear dry mass plotted against chromosome volumes. Code as in previous figures.

increasingly compact, with increasing ploidy. As suggested earlier the compaction is probably the result of increased metaphase coiling and may well serve an adaptive function (Darlington, 1937).

A shorter chromosome length in the polyploid wheats has been reported by others (Marshak and Bradley, 1944; Swaminathan and Natarajan, 1957; Bhaskaran and Swaminathan, 1960). It must be emphasised, however, that the shorter length does not, as has been claimed, reflect a diminution 
in chromosome material. It simply reflects a re-distribution of chromosome material.

(c) Nucleolar mass and nuclear DNA

In fig. 6 are the nucleolar dry mass values observed in the diploid and polyploid species and the values expected in the tetraploid and hexaploid

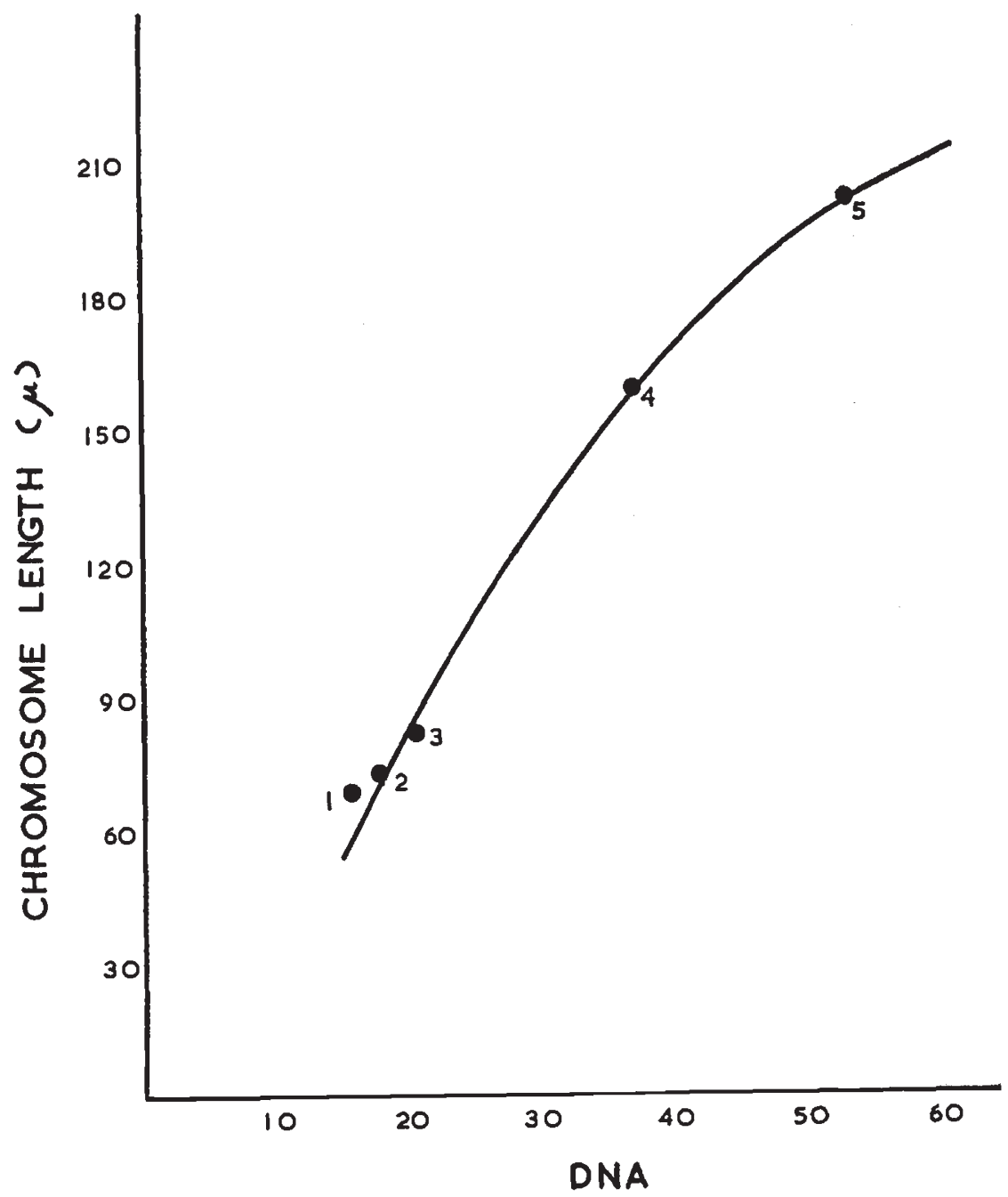

Frg. 4.--Total chromosome length at metaphase plotted against nuclear DNA. Code as in earlier figures.

from summing the diploid values. It is clear that the nucleolar mass in the tetraploid and hexaploid is not a straightforward sum of the diploid values. Without more information about the chemistry of nucleolar activity it would be unprofitable to speculate further on the significance of this observation. 
It is, however, worth noting that the nucleolar product is not directly correlated to the amount of nuclear DNA.

\section{Summary}

1. The divergence and evolution of diploid species within the Triticinae was associated with change in the volume of chromosomes, their mass and DNA content.

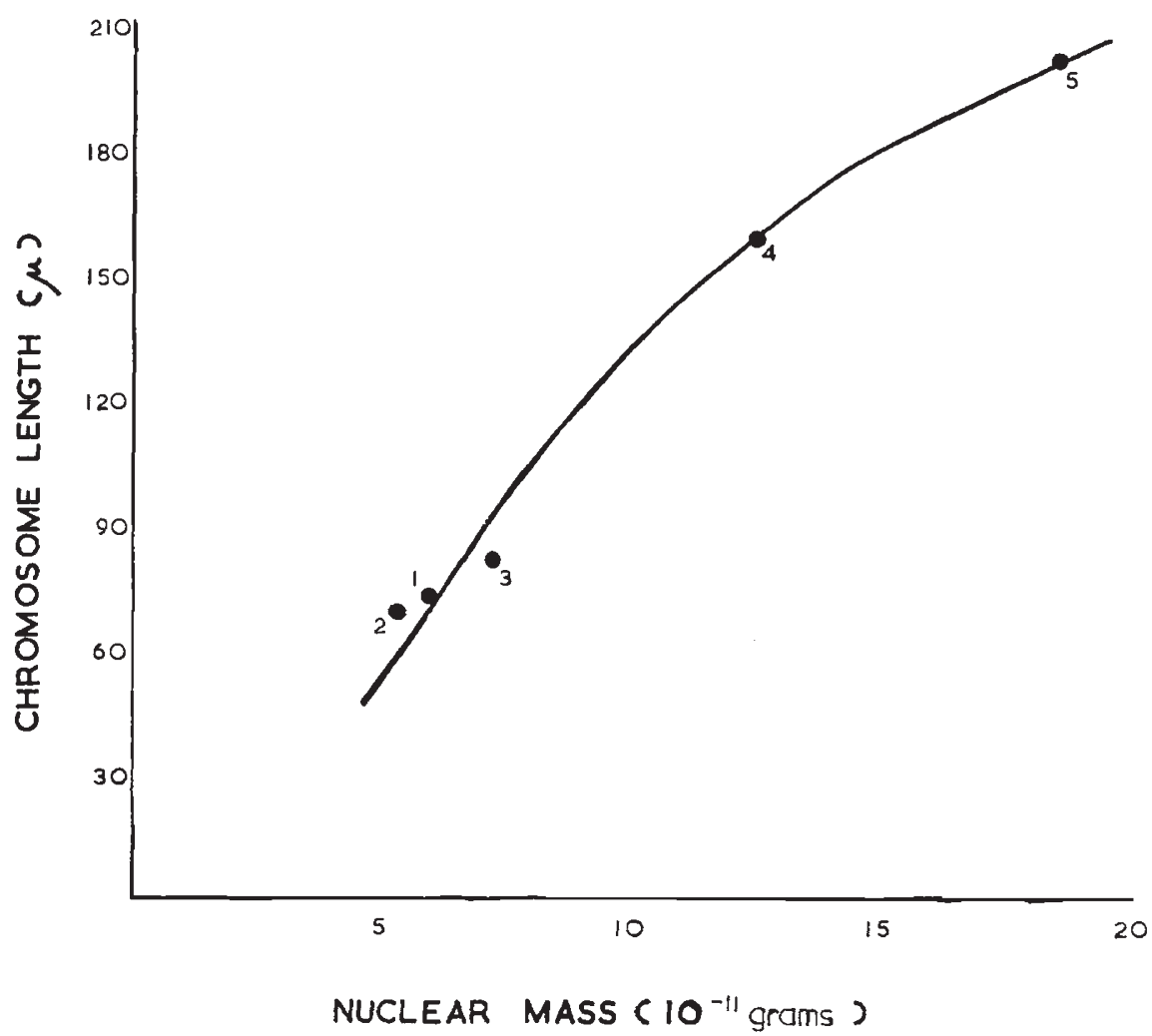

FIG. 5.-Chromosome length at metaphase plotted against nuclear dry mass. Code as in earlier figures.

2. There is no detectable change in chromosome volume, mass or DNA in conjunction with the hybridisation and polyploidy which gave rise to the cultivated species.

3. Chromosomes in the hexaploid, Triticum aestivum, are shorter than in its tetraploid and diploid ancestors. The contraction is not, as has been claimed, a reflection of a diminution in the chromosome material but, rather, of its reorganisation.

4. Comparisons between species show that the chromosome volume, dry mass and DNA content are linearly related. The linearity testifies to the constancy of each component relative to the other throughout the group.

5. The mass of the nucleolus is disproportionately low in polyploids as compared with diploids. 


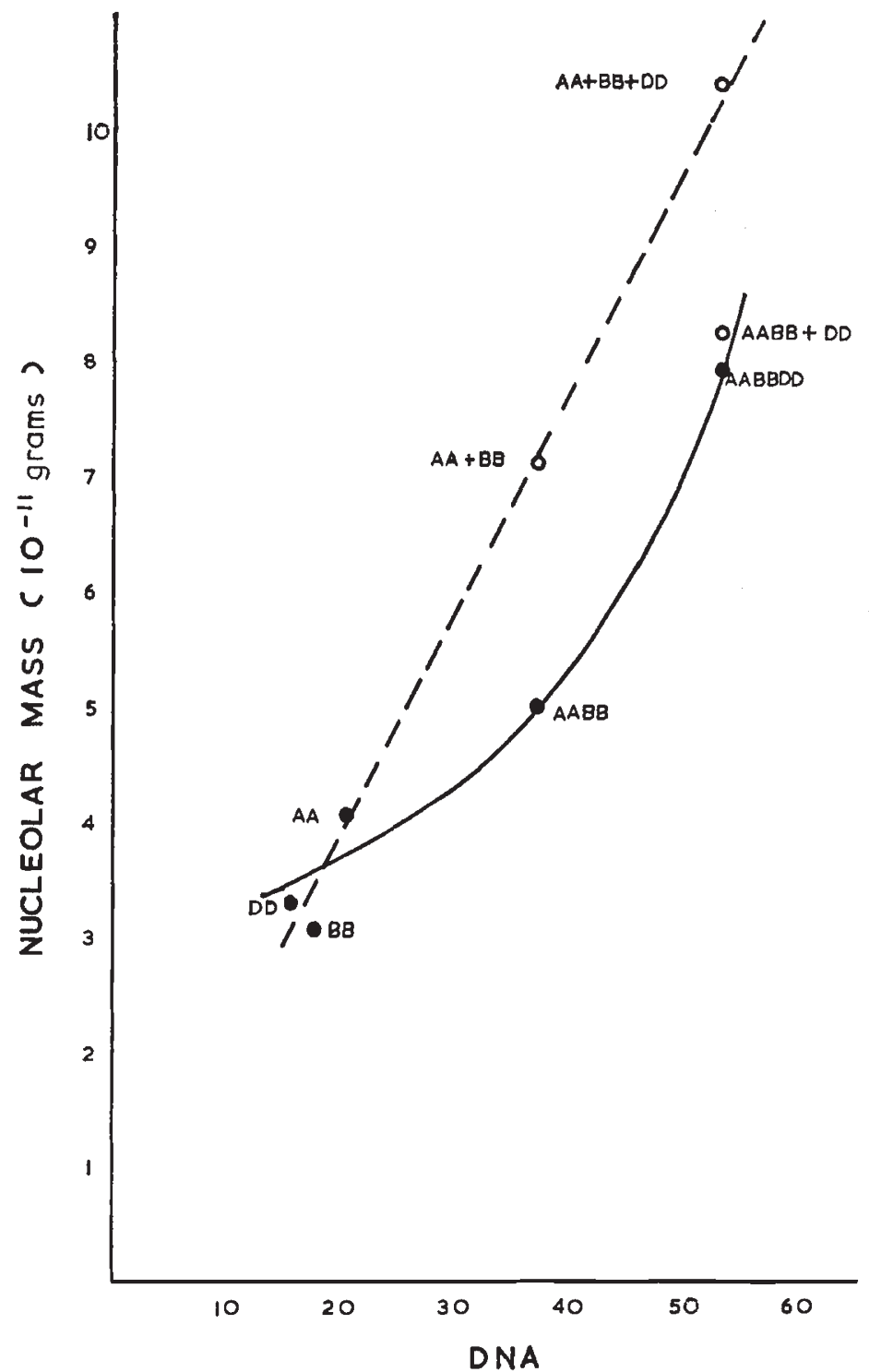

Fro. 6.-Nucleolar dry mass plotted against DNA. Dotted line = " expected values"; Solid line $=$ observed values.

\section{REFERENCES}

BARER, R. 1956. The interference microscope in quantitative cytology. Supplement to 2nd Ed. The Baker Interference Microscope.

BENNETT, M. D., AND REES, H. 1967. Natural and Induced changes in chromosomes size and mass in meristems. Nature. Lond., 215, 93-94.

Bhaskaran, s., AND swaminathan, M. s. 1960. Polyploidy and radiosensitivity in wheat and barley. Genetica, 31, 449-480.

DARLington, c. D. 1937. Recent Advances in Cytology. Churchill, London. 
DAVIES, H. G. 1958. The determination of mass and concentration by microscope interferometry. In General Cytochemical Methods, Vol 1. Academic Press Inc.

JEnkins, J. A. 1966. The origin of cultivated wheat. Can. F. Genet. Cytol., 8, 220-232.

LILIENFIELD, F. A., AND KIHARA, H. 1934. Genomanalyse bei Triticum und Aegilops. V. Triticum timopheevi Zhuk. Cytologia, 6, 87-122.

MARSHAK, A., AND BRADLEY, M. 1944. X-ray inhibition of mitosis in relation to chromosome number. Proc. Nat. Acad. Sci. US., 30, 231-237.

MCLEISH, J. 1963. Quantitative relationships between deoxyribonucleic and ribonucleic acid in isolated plant nuclei. Proc. Roy. Soc. B, 158, 261-278.

PAI, R. A., AND sWaminathan, M. s. 1960. Differential radiosensitivity among the probable genome donors of bread wheat. Evolution, 14, 427-432.

REes, H., CAMERon, F. M., HAZARIKA, M. H., AND JONES, G. H. 1966. Nuclear variation between diploid angiosperms. Nature Lond., 211, 828-830.

REES, H., AND WALters, M. R. 1965. Nuclear DNA and the evolution of wheat. Heredity, 20, 73-82.

RILEY, R., UNRAU, J., AND CHAPMAN, v. 1958. Evidence on the origin of the B genome of wheat. F. of Heredity, 49, 91-98.

RothFELS, K., SEXSMITH, E., heIMBURGER, M., AND KRAUSE, M. O. 1966. Chromosome size and DNA content of species of Anemone L. and related genera (Ranunculaceae). Chromosoma (Berl.), 20, 54-74.

swaminathan, M. s., AND natarajan, A. T. 1957. Polyploidy and Radiosensitivity. Nature, $179,479-480$.

UPADYA, M., AND SWAMinathan, M. s. 1963. Deoxyribonucleic acid and the ancestry of wheat. Nature, 200, 713-714. 